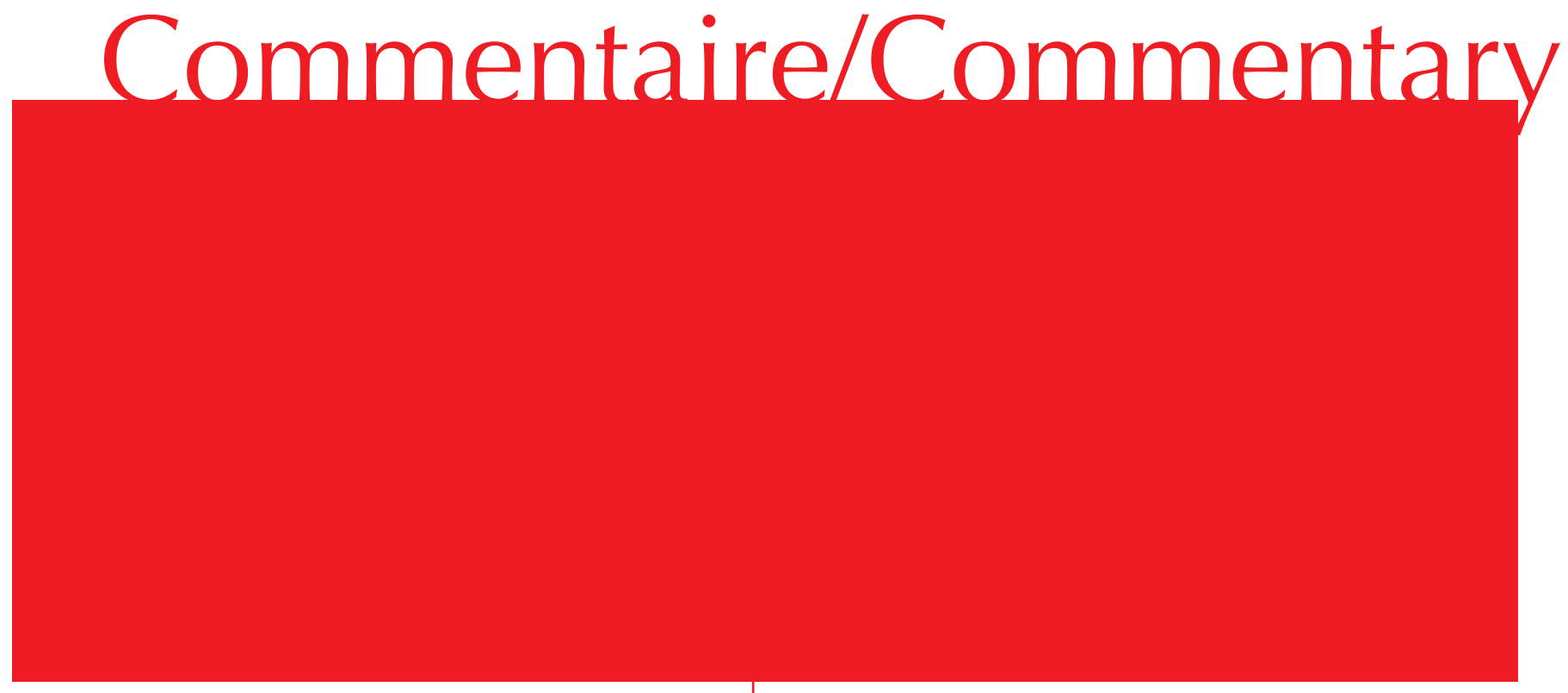

\section{Recent Case Raises Hopes for Reducing Harm from Psychiatric Labelling: A Blow Against "Weaponized Diagnosis"}

\section{PAULA J CAPLAN \& KADE PATTERSON}

\section{Harm from Psychiatric Diagnosis}

A person can suffer a vast array of kinds of harm as a result of being labeled mentally ill. $[1,2,3]$ The harm can range from plummeting of one's self-confidence to loss of a job or failure to get one to loss of custody of one's children to deprivation of the rights to make decisions about one's medical and legal affairs. Such labeling can be used as a way to discredit and silence those who speak out about matters that those more powerful than they wish to keep secret. In addition, once psychiatrically diagnosed, a person who has real physical illnesses, pains, or injuries may have those problems overlooked or dismissed as the imaginings of a person who is mentally ill. It is frighteningly easy to trample on a person's basic human rights once they have been classified as mentally ill.

As long as this labeling happens in places where sexism and other forms of bias and oppression persist, the damage will continue to be disproportionately done to those who are not male, white, heterosexual, reasonably well-off financially, neither very old nor very young, and ablebodied.[1,4] Especially troubling is that many therapists diagnose someone as psychiatrically disordered when in fact the behavior and emotions they classify as evidence of mental illness are the deeply human (even in important ways "normal"[1]) reactions to traumatic experiences such as being raped or being in a war zone. In some settings, as will be discussed, additional factors are breeding grounds of still other forms of harm. It is encouraging that recent developments in one such setting provide reason for guarded optimism about the possibilities for reducing the harm. 
The fundamental issues addressed in this paper apply directly to anyone psychiatrically labeled in any country, although the primary, encouraging case example we present is about one of the co-authors (KP), who served in the United States Army. Once as massive and powerful an institution as the U.S. Army changes course, it is hoped that other institutions will follow suit. At best, recent action by the U.S. Army will turn out to be a harbinger of such a change.

Description of the specifics of the Patterson case will be presented, followed by discussion of some principles that apply to such cases both in and out of the military and also of issues particular to the military.

\section{The Patterson Case}

Kade (then known as Katie Leigh) Patterson had achieved a fine record of military service and was proud of being part of the U.S. Army since enlisting in August, 2004. Then in 2005, a sergeant sexually assaulted her on their base. In the U.S. military, victims who wish to report such attacks are required to do so within their chain of command, although that chain often includes the perpetrators themselves and/or people whose priority is to protect the reputation of their unit rather than seeking justice for the victims and appropriate punishment for the perpetrators. Patterson reported the assault within her chain of command, and the report went to the office of the Army's Judge Advocate General (JAG). An order was issued restraining the sergeant from coming near her. Patterson requested a copy of the JAG's file about the case, and the JAG refused to give it to her. She continued to do her work and did not seek help from a therapist at that time. The same year, while outside the base, she was again sexually assaulted. Immediately, she went to the nearest hospital - a civilian one - reported having been raped, and was interviewed and examined. At her request, the hospital gave her a report of this visit.

When Patterson learned that her second assailant had previously done military service, her deep-seated faith in the Army as an institution where people behaved with integrity was shattered, and for the first time in her life, she became frightened, agitated, and despondent to the point of thinking about committing suicide. She told her battle buddy how she was feeling, and when the battle buddy reported this within their chain of command, Patterson against her will was sent to a civilian mental hospital outside the Army base and told by the Army that she was not allowed to leave. Needless to say, servicemembers know they are expected to follow orders. She was placed in a padded room and given no support or counseling. She was put on five or six psychiatric drugs and does not recall what the drugs were but remembers sleeping almost constantly for the entire 30 days in the hospital. She does not recall anyone from the Army meeting with her during her hospital to stay to offer information, support, or counseling. She felt that she was having a normal reaction to trauma and had done nothing wrong but was being punished. She was held there without being given a formal hearing or told she could have one and was informed that she had to stay until she was no longer a danger to herself or anyone else. She had never considered harming anyone else. Although she must have been given at least one psychiatric diagnosis when admitted to the hospital, she does not recall being told anything while there about receiving any labels. When she later signed and sent forms requesting her records from that hospital, the reply she received was that her records were sealed and that she could not have them. It is not known whether the Army was given the records or who ordered them sealed.

Patterson was told that she was being released from the hospital because she was no longer considered dangerous. When she returned to the base, an enlisted woman in the orderly room who was not a counselor or therapist informed her that the Army was saying she had Personality Disorder with Borderline Features. Patterson does not know where that information came from, but she then saw a psychologist/ lieutenant for 30 minutes, during which he asked her some questions, she tried to bring up the assaults, and he avoided discussing them and simply kept repeating that due to her self-harming behavior (though she had never made such an attempt), she was not adapting to military life and culture. Borderline Personality Disorder (BPD) is one of the most harmful of all psychiatric labels because of the serious impairments in many kinds of functioning that are said to characterize it, and women are far more likely than men to be given this diagnosis. [5]

Subsequently, an officer in Patterson's chain of command informed her that she was going to be discharged from the military, and when Patterson said she wanted to see a lawyer, the officer told her if she was unwilling to accept being discharged on the basis of her diagnosis, she would be dishonorably discharged. As a result, Patterson agreed to the discharge on the basis of the diagnosis, because it would be classified as honorable. Patricia Lee Stotter, a veterans' advocate and co-producer of the film "SERVICE: When Women Come Marching Home," coined the term "weaponized diagnosis" to describe exactly this kind of use of psychiatric labeling to blame and otherwise harm victims of sexual assaults and other kinds of trauma [6]. The term is 
applicable to people who are treated this way in the civilian world as well.

The U.S. Army has a Board of Appeal for Correction of Military Records (ABCMR). In 2013, Patterson first learned about the existence of this Board after being in touch with other survivors of military sexual trauma and then searching online. That year, on her own, she appealed to that Board to remove the personality disorder basis for her discharge. She provided documentation that she had had no history of emotional difficulties before the assaults and that being upset because of being attacked does not warrant a diagnosis of mental illness and certainly not of a personality disorder. The Army rejected that appeal, saying that its own physician did not believe that her documentation warranted removal of the diagnostic label. There were many troubling aspects of the physician's opinion, including his lack of access to the full information and his unwarranted inferences. For instance, he cited the fact that Patterson had been prescribed powerful psychiatric drugs after the assaults as indicating that she was mentally ill, with no sign that he had considered the possibility that she was not mentally ill and that the drugs were unjustifiably prescribed. He also presented as a concern that Patterson "fired" a VA therapist who doubted the veracity of her report that she had been sexually assaulted, when in fact it is not just appropriate but actually advisable for a patient to stop seeing a therapist who would do that. According to Patterson, she stopped seeing that psychologist after giving her a copy of the official report of the second rape that was prepared at the off-base hospital near where the assault occurred, and the psychologist, after accusing her of having created it on her own computer, actually ripped it up. Furthermore, this same therapist had done no evaluation of her own but told Patterson she had a personality disorder because the Army had decided that she did.

In 2014, this time with assistance from attorneys with whom she had been connected by Protect Our Defenders which advocates for victims of sexual assault in the military, Patterson again appealed, adding still more documentation of her excellent psychological functioning previous to the assaults. Ten years after her discharge, in a groundbreaking reversal, the ABCMR in March, 2015, granted her appeal, removing the personality disorder diagnosis as the reason for discharging her. As her attorneys requested, the discharge reason was changed to "Secretarial Authority," which indicates that her release was part of downsizing by the Secretary of the Army.

Despite the primarily positive move, the Army's recent decision is somewhat problematic. First, her counsel had noted that Patterson had been a victim of sexual assault, but the Army's section about reasons for their changed decision fails to include mention of that, referring only generally to her having experienced "a traumatic event," which might be taken to mean the one in which she sustained traumatic brain and knee injuries. Curiously, the decision includes in one sentence the contradictory statements that she "had developed a personality disorder," although by definition that does not happen in adulthood, and that as the result of that disorder, she had problems "that began prior to service." In addition, a counselor Patterson saw at the Vet Center wrote to the ACBMR that Patterson does not have a personality disorder but instead suffers from PTSD secondary to the sexual assaults. Although it is certainly true that Patterson suffered as a result of the assaults, it is problematic to diagnose her with PTSD, given that PTSD is an official psychiatric disorder, so the Vet Center counselor was simply applying a different psychiatric label to Patterson's normal reactions.

The ACMBR has a website on which 13 cases were located of women sexual assault victims who had been diagnosed with BPD and discharged on that ground and who requested removal of that reason for discharge. [8] For only two has that request been granted. Patterson's is the more recent of those two. A similar ABCMR decision changing personality disorder to Secretarial Authority as the reason for discharge of a sexual assault victim [9] was made less than one month after the Board's 2013 rejection of Patterson's first appeal, and it is unclear from their written decision why the Board took almost two more years to make the change for Patterson. When they were asked to explain why this was, they refused to reply.[7]

When asked why no mention is made in the Discussion and Conclusions section of the Board's March 10, 2015 decision of Patterson's statements about having been sexually assaulted in the military, the Army representative's reply was that the reasons for the decision would not be discussed, that "the collective reasons by the ABCMR panel" are contained in the document about its decision, and that "To comment beyond the Record of Proceedings would be speculative and intrude upon the deliberative process of the Panel." [7] In this regard it is relevant that investigative journalist Alissa Figueroa has shown massive and blatant problems with the ACBMR's procedures, including that they do not read much of what appellants submit and that they spend an average of three minutes and 45 seconds on a case before rendering their decision.[10] 


\section{Crucial Issues: Unknowns and Injustices}

Psychiatric Diagnosis Is Unregulated. It is impossible to know how many traumatized people in or out of any military or civilian system have been labeled mentally ill on the basis of the emotional or behavioral effects of trauma and have suffered harm because of receiving those labels. At the most general level, this is due to the rarely-discussed but important fact that psychiatric diagnosis is entirely unregulated. The two primary diagnostic manuals - the American Psychiatric Association's (APA) Diagnostic and Statistical Manual of Mental Disorders (DSM)[10] and the World Health Organization's International Classification of Diseases ([11] the latter of which includes a psychiatric section that is intentionally similar to the contents of the DSM) - are created by committees deliberating largely in secret. Nine complaints filed with the APA's Ethics Committee about devastating harm done to individuals by the use of DSM labels and the false advertising of the DSM as scientifically based were curtly dismissed by that Committee on highly spurious grounds and with no attention paid to the merits of the cases. [13, 14] Five of those complainants then filed with the Office of Civil Rights of the U.S. Department of Health and Human Services, alleging that they had been discriminated against pursuant to the Americans with Disabilities Act, relative to the provision prohibiting the treatment of people without disabilities as though they have disabilities. The complainants had experienced events ranging from deeply troubling to horribly traumatic, and their reactions to those events - as with Patterson - were used to diagnose them as psychiatrically disordered. Those complaints were also dismissed on patently unwarranted grounds, again with no attention to the merits of the cases. [13, 14] And attempts even to find out whether the World Health Organization has a committee with whom such complaints can be filed have been met with stonewalling. [15]

Scope of Harm is Unknown. One consequence of this lack of regulation both by the APA guild and the U.S. government entity that ought to provide oversight and act on complaints about harm is that no central, accurate recordkeeping of who gets diagnosed and with what label exists. And although the nine complainants in the APA cases requested that the APA actively begin - as drug companies have been ordered to do in the U.S. - to compile records of harm from their product, the DSM, they have not done so. The APA might consider using some of the $\$ 100$ million earned from the DSM-IV to gather this information.

It is impossible to determine how many sexual assault victims in or out of the military have had their normal upset classified either as any psychiatric disorder or specifically as BPD. Outside of the military, there is no central system of such records, and between 2001 and 2010, the military discharged more than 31,000 servicemembers on the basis of their having been diagnosed with personality disorders of various kinds, but the military has refused to release information about the "scope and nature" of these cases. [16] The Army specifically has written that it does not have data to show the specific reasons for discharge in cases that are appealed to them. [7]

Furthermore, Patterson's experience with the psychologist who changed the subject when she tried to talk about having been assaulted remains all too common in both the military and civilian realms: Despite decades of work beginning with Second Wave feminists who began to speak out about sexual violence, intake forms and inpatient and outpatient charts - in the civilian world as well as in the military - too often include little or no mention of such trauma as causes for upset. Some therapists remain unwilling to address or even allow patients to discuss sexual assaults, and many are inclined to pathologize normal reactions to such assaults. In something of the same way that Patterson's Army psychologist considered her upset a sign of her failure to adapt to Army culture, some civilian therapists pathologize victims who remain upset beyond the time that the therapist deems they should have "recovered."[17]

The Public and Professionals Are Unaware of the Facts about Psychiatric Diagnosis. Another consequence of the lack of regulation is that much of the public across the globe and even surprisingly many therapists and other professionals are unaware of the solidly-documented facts that psychiatric diagnosis is almost entirely unscientific, that applying the labels does not reduce the suffering of those who are so labeled, and that getting a label carries many risks of harm. $[1,13,14]$ As a result, like most people in a mental health system, Patterson was unaware of these facts and therefore in no position to challenge either the fact that she was diagnosed as mentally ill or the specific label she was given.

By definition, personality disorders are considered lifelong conditions, but despite Patterson's history of excellent functioning before the assaults, not for many years did it occur to her to challenge her diagnosis. In this respect, she is similar to most people who have this series of experiences. This is because therapists are so widely assumed to be experts who are making scientifically-based judgments and implementing scientifically-validated treatments.[13,14] 
Furthermore, going through the assaults, the further trauma of the ways she was then wrongly treated and not given the support and understanding that would have been appropriate and helpful, then being discharged from the military she loved left her for many years too stunned and too busy totally reorienting her life even to explore if or how she might seek redress.

Procedures and rules specific to the U.S. Army made it impossible for Patterson to obtain essential documentation for her appeals, but many people in the civilian world in many countries have found met with long delays and even denials when they have requested their mental health records. This has quite likely reduced the numbers of people who have ever formally or informally asked any practitioner or representative of a clinic, hospital, or other entity to remove a psychiatric diagnosis from their files.

Problems Specific to the Military. Nancy Parrish and Paula Coughlin of Protect Our Defenders have written: "Instead of assuring victims that their distress about their attacks is a normal response, the Department of Defense (DoD) has a record of mistreating victims by labeling them with errant diagnoses of personality or adjustment disorders. Based on these diagnoses, victims are not only further stigmatized, but often discharged without benefits or health care".[18] They also note that although since 2001, more than 31,000 servicemembers were discharged based on PD labels, [16] in fact the Army, Navy, and Marine Corps "do not properly track mental health discharges." [19]

In 2012, U.S. Congresswoman Jackie Speier proposed a legislative amendment that would have directed the Department of Defense (DoD) to review the cases of people who were discharged from the military since 2001 on the grounds that they had been labeled with personality disorders, and it has been proposed that Adjustment Disorder diagnoses also be reviewed, since both are applied to sexual assault victims.[20] At issue for Speier was that cases of military sexual assault were then and are still very rarely being prosecuted[17] and that the Congresswoman had heard from many victims who not only saw their perpetrators go unpunished but who had themselves been retaliated against by being labeled mentally ill and suffering further because discharges on that basis made them ineligible for compensation and services.

This proposal was groundbreaking, but action needs to be taken against more than these two categories of diagnosis, because the kinds of harm described at the beginning of this commentary can come to a person who receives any psychiatric label. In some respects, the personality disorders are the most damaging labels for military veterans, because some substantial benefits are granted only to people with what are called "service-connected" problems, those resulting from or occurring during military service. The Adjustment Disorder (AD) category, although not classified as a personality disorder, constitutes labeling the person as having an abnormal response to what has happened to them; this is precisely because AD is officially considered a mental illness because of its listing in the diagnostic manual. Many other victims - of sexual assault, of war trauma, or of other kinds of trauma - receive any of a wide variety of other psychiatric labels, all of which involve calling normal reactions pathological. This includes Acute Stress Disorder, Major Depressive Episode, Major Depressive Disorder, Generalized Anxiety Disorder, and the extremely frequentlyused Post-traumatic Stress Disorder. By virtue of their appearance in the manual, each of these is used to convey the inaccurate and harmful message that the traumatized person should not have been affected by the trauma.[17]

It is noteworthy that a 2015 Yale Veterans Clinic report[16] had shown that when, beginning in 2007, the military was criticized for using PD labels to deprive people of benefits and services, their use of those labels dramatically declined, but at the same time, their use of the AD label skyrocketed. In the Army, for instance, since 2008, as the numbers of PD discharges declined from nearly 1,000 previously to just over 300 per year, their discharges based on AD skyrocketed to 2,000 per year. All psychiatric diagnoses need to be included in such counts.

\section{Is the "PTSD" Diagnosis a Good Solution?[21]}

Patterson and other trauma survivors - in both the civilian and the military realms - have been advised to try to get their other psychiatric labels changed to "Post-traumatic Stress Disorder." There are three reasons for this. One is that getting that label seems an improvement over what seem to be more serious-sounding labels and that the inclusion of "trauma" in the title suggests that there is a reason other than a diseased brain for their feelings and behavior. A second is that getting that label can be a way for them to receive benefits if they can show that the trauma occurred during their military service, and a third is that the label qualifies them to receive certain services. With regard to the first, their relief about being diagnosed in a way that seems to be less damning and less permanent than a personality disorder in particular - often understandably leads them to being unguarded about the other kinds of harm that can result from getting any 
psychiatric diagnosis. With regard to the second, of course people harmed in the military should receive benefits, but being psychiatrically diagnosed should not have to be the way they get those benefits; the fact that they are suffering from what happened should be sufficient. As for the services to which the PTSD label (and others) can help them gain access, the rampant problems and delays in services from the VA are widely known, one of the two most common services - psychotherapy - is sometimes but often not helpful, and the other most common treatment - psychotropic drugs - has been shown to be helpful to some people but to do more harm than good. [22]

PTSD is as official a listing in the diagnostic manuals as anything else therein. [21] When it first went into the DSM, it included a statement to the effect that these were normal reactions to abnormal experiences. That was rather bizarre, because if the criteria listed for "PTSD" were normal reactions, then what was the label doing in a manual of mental illnesses? But at least that sentence made it possible for people who got the diagnosis to consider that they were not mentally ill, that they should not have "gotten over it" by now. Stunningly, in the 1994 edition of the DSM, [23] under the stewardship of DSM-IV head Allen Frances, that sentence was simply removed.

Before the term "Post-traumatic Stress Disorder" was created after the American war in Viet Nam in a well-intended attempt to draw attention to veterans' suffering, the other terms to describe war had each included a word that accurately represented the cause of the suffering: The term used in the U.S. Civil War was "soldier's heart," and others have included "war trauma," "combat stress," "shell shock," and "battle fatigue." The first word of PTSD is vague and certainly downplays the role of war in causing trauma. The same is true when "PTSD" is applied to a victim of sexual assault, who would more accurately be described as suffering from "rape trauma."

As for the "S" in "PTSD," the word "stress" is used to apply these days to everything from worry about being a few minutes late for an appointment to devastating experiences. What traumatized people experience tends to include some or all of the following: grief, terror, loss of innocence, shame, powerlessness, and despair.[21] To call those "stress" is both overly general in a way that is unhelpful to the labeled person and those who want to help them and minimizing of the suffering.

The " $\mathrm{D}$ " in the term applies the official stamp that makes it a mental illness.

\section{Are There Reasons for Optimism about the Future?}

There are reasons for concern but also some reasons for optimism about the future for people who are diagnosed as mentally ill because it upset them to be sexually assaulted.

Reasons for concern across the civilian and military realms include:

- the widespread belief that psychiatric diagnoses are scientifically-derived and applied, are helpful, and are not harmful

- the common tendency for people - both the public and many mental health professionals - to believe the myth that emotional problems are usually or always caused by chemical imbalances or defective brains and thus need to be psychiatrically diagnosed in order to be effectively treated

-the fact that devastation and a sense of powerlessness and shame can result from being sexually assaulted and also from being classified as mentally ill, thus reducing the chances that victims will challenge - or even wonder about - being diagnosed or be able to try to undo the harm that results

-the public's lack of awareness of how to get a diagnosis removed from their records, combined with the paucity of attorneys who assist with such efforts

A primary reason for concern within the U.S. Army is their statement that "as an Agency, we cannot provide advice to any applicant in any case for maximizing the chances for a successful outcome." [7] Although they would likely justify this statement by saying that would be tantamount to any court giving advice to people about how to win their cases, the fact that few military servicemembers and veterans even know of the existence of military boards of appeals for correction of records, never mind what they should include in an appeal and the difficulty of finding attorneys to represent them, combines with the boards' apparent freedom to conduct their business according to their own, undisclosed rules and procedures to stack the deck against appellants.

In both the military and civilian realms, one way to consider the future is to list some changes that could help reduce the harm that comes to sexual assault victims who are psychiatrically diagnosed and then suffer harm as a result. These include:

-educating the public and professionals about the facts that psychiatric diagnoses are unscientific, largely 
unhelpful, and often harmful[1,13,14,24] ${ }^{\mathrm{i}}$

- calling the public's attention to the ways that our world has become "psychiatrized" to the point that deeply human reactions to trauma that should by no means be labeled as pathological are often labeled that way[1]

- encouraging attorneys around the globe to represent those who have been harmed by psychiatric diagnoses in seeking to have the labels removed from their files and various forms of harm redressed

- holding U.S. Congressional hearings and hearings by legislative bodies in other countries about psychiatric diagnosis as an important step toward creating systems of oversight and regulation

- widely publicizing the important 2015 press conference by Human Rights Watch about the virulent forms of retaliation in the U.S. military against sexual assault victims who report the attacks, with the pathologizing of them as mentally ill named as one of the key forms[25]

- implementing careful oversight and wide publicizing of the decisions of military boards of appeal that deal with these cases and informing military servicemembers of the existence of these boards

These are only a few of many possible steps that would have significant impact on preventing harm from psychiatric diagnosis and letting those who have been harmed know what can be done to help them get justice. The Patterson decision paves the way for a sorely-needed look at the use of psychiatric labels to discredit people, cause them material harm, and deprive them of their human rights.

\section{Notes}

'Although U.S. National Institute of Mental Health Director Thomas Insel in this essay sharply criticizes the DSM system, the different system he vigorously promotes here is also profoundly flawed.

\section{References}

1.Caplan PJ. They say you're crazy: How the world's most powerful psychiatrists decide who's normal. Reading, MA: Addison-Wesley, 1995.

2.Caplan PJ. (2014). When you try to speak truth to power, what happens if the powerful turn off their hearing aids? In D. Holmes, J.D. Jacob, \& A. Perron (Eds.), Power and the psychiatric apparatus: Repression, transformation, and assistance. Surrey: Ashgate; 165-81.
3.Human Rights Implications of Psychiatric Diagnosis symposium. Center for Human Rights and Humanitarian Law, Washington College of Law. https:/www.youtube.com/ watch?v=noHrEt4a5IQ .

4.Caplan PJ \& Cosgrove L (Eds.). Bias in Psychiatric Diagnosis. Jason Aronson/Rowman \& Littlefield, 2004.

5.Janacek B \& Caplan PJ. Does Borderline Personality Disorder exist? What the data show. Unpublished paper, Harvard University.

6.Stotter PL. Personal communication with Paula J. Caplan. January 23, 2013.

7.Prince, PD, Deputy Director of Public Affairs, Manpower \& Reserve Affairs, Army G-1, Pentagon. Email to PJ Caplan. May 182015.

8.Army Board for Correction of Military Records. Search conducted by authors on May 31 2015. http:// boards.law.af.mil/cgi-bin/htsearch?restrict $=$;exclude $=$;c onfig=ARMYBCMR_htdig; method=and;format=builtinlong; sort=score; words=borderline $\% 2$ ppersonality $\% 20$ sexual;page $=3$ )

9.Army Board for Correction of Military Records. Search conducted by authors on May 31 2015. (http://boards.law. af.mil/ARMY/BCMR/CY2013/20130006508.txt)

10.Kors J. Investigative reporter Alissa Figueroa exposes stunning flaws in veterans' benefit system. Huffington Post. December 28, 2014. http://www.huffingtonpost.com/joshuakors/investigative-reporter-al_b_6382880.html Accessed May 312015.

11.American Psychiatric Association. Diagnostic and Statistical Manual of Mental Disorders-5. Washington, DC: American Psychiatric Association, 2013.

12.World Health Organization. International Classification of Diseases-10. http://apps.who.int/classifications/icd10/ browse/2015/en Accessed May 312015.

13. Caplan PJ. The APA refuses to listen to the voices of those harmed by diagnosis... and refuses and refuses. Mad in America: Science, Psychiatry, and Community. November 19.http://www.madinamerica.com/2012/11/the-apa-refusesto-listen-to-voices-of-people-harmed-by-diagnosis-andrefuses-and-refuses-and-refuses/\#comment-17784 Accessed 17 January 2015.

14.Caplan, PJ. (2012). Will the APA listen to the voices of those harmed by psychiatric diagnosis? Mad in America: Science, Psychiatry, and Community. October 1. http://www. 
madinamerica.com/2012/10/will-the-apa-listen-to-thevoices-of-those-harmed-by-psychiatric-diagnosis/. Accessed Jan 172015.

15.Emails from Dr Robert Jakob, Medical Officer (ICD), IER/HSI/CTS, Classifications, Terminologies, and Standards. Geneva, to Paula J. Caplan. February 7 and 10, 2013.

16.Ader, M, Cuthbert, R., Jr., Hoechst, K, Simon, EH, Strassburger, Z, \& Wishnie, M. Casting Troops Aside: The United States Military's Illegal Personality Disorder Discharge Problem; 2012. http://www.vva.org/PPD-Documents/ WhitePaper.pdf Accessed May 312015.

17.Caplan, PJ. Sexual trauma in the military workplace: Needed changes in policies and procedures. Women's Policy Journal of Harvard 10, 10-21, 2013.

18.Parrish, N, \& Coughlin, P. Destruction of lives with the stroke of a pen. Disruptive Women in Healthcare. March $102015 . \quad$ http://www.disruptivewomen.net/2015/03/10/ destruction-of-lives-with-the-stroke-of-a-pen/\#more-19670 Accessed May 312015.

19.Kime, P. GAO: Shortfalls in tracking mental health discharges. Military Times. March 2, 2015 http:// www.militarytimes.com/story/military/benefits/ health-care/2015/03/02/gao-pentagon-mental-healthdischarges/24262045/ Accessed May 312015.

20.Speier, Congresswoman J. Press release: Statement: Congresswoman Jackie Speier on House Committee Passage of National Defense Authorization Act and Inclusion of Her Amendments. May 10, 2012. http://speier.house.gov/index. php?option $=$ com_content $\&$ view $=$ article $\& i d=645$ :statementcongresswoman-jackie-speier-on-house-committee-passageof-national-defense-authorization-act-and-inclusion-of-heramendments\&catid=20\&ltemid=14 Accessed May 312015.

21.Caplan, PJ. When Johnny and Jane come marching home: How all of us can help veterans. Cambridge, MA: MIT Press, 2011.

22.Whitaker, R. Anatomy of an epidemic. New York: Random House, 2010.

23.American Psychiatric Association. Diagnostic and statistical manual of mental disorders-IV. Washington, D.C.: American Psychiatric Association, 1994.

24.Insel, T. Director's blog: Transforming diagnosis. April 29, 2013. http://www.nimh.nih.gov/about/director/2013/ transforming-diagnosis.shtml Accessed May 312015

25.Human Rights Watch. Military sexual assault report. (press conference) May 18, 2015. http://www.c-span.org/ video/?326106-1/discussion-military-sexual-assault-report.

Acknowledgements

Gratitude to Amy Smith, Terri Youngs, Amy Quinn, Patricia Lee Stotter, and Colleen Bushnell for their help with this article.

To contact the authors:

Paula J. Caplan, Ph.D.

Associate

Harvard University

DuBois Research Institute of Hutchins Center

United States of America

Email: paulacaplan@gmail.com

Kade Patterson

Indiana State University 